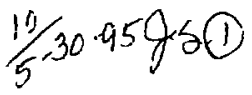

\title{
FAST FEEDBACK FOR LINEAR COLLIDERS
}

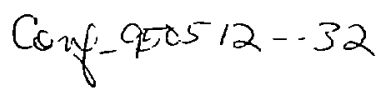

\author{
L. Hendrickson, C. Adolphsen, S. Allison. T. Gromme, P. Grossberg, T. Himel, K. Krauter. \\ R. Mackenzie. M. Minty, R. Sass, H. Shoaee and M. Woodley
}

Stanford Linear Accelerator Center. Stanford University. Stanford, California 94309 *

\begin{abstract}
A last fecdhask system provides beam stabilization for the SLC. As the SLC is in some sense a protolype for future linear colliders, this system may he a pretotype for future leedhicks. The SLC provides a good base of experienee lor leedhack requirements and capahilities as well as a testing ground for performance characteristics. The feedback system controls a wide variety of machine parameters throughoul the SLC and associaled experiments. including regulation of heam position. angle. energy. intensity and timing paramelers. The design and applicusions of the system are descrihed, in addition to result of recent performance studies.
\end{abstract}

\section{NTTRODUCTION}

In four years of operalion. the SLC feedhack system has cxpinded from an nriginally-planned cight linus launch lenp 10 nicarly. 50 cunirol lomps in every major arca of the SIC as well as special experiments and diagnostic lonps. Due it the distahase-dricen design, neu control hoops are easily implemented usually withoul requiring software chariges. The system. descrihed more fully elsewhere|1|. is generalized and supporis the use of existing control system elements. uivally ujthout requiring the additior. of dedicaled harduare. The control bigorithm is hased on the rtate space fonmalism of digital control theory [6].

The pulsed electron and pasitron bunches in the SLC are generuted at 120 Hers. While some of the feedhask loops operate at the full heum rale. others run at lower rates (1):peally 20) Herles mainly due to CPU and heam pessition monuter (BPM, limitulions. The real-time functions rurs on Inicl 80386 and 80486 microcomputers (mictos) which are distrihuted geographicatly. In the SLC control system, the micros do nol ordinarily communicate with cach olher: 10 facilitate intermicro communication for the feedhack system. a specialized poinl-to-poin! neiwork was added[3].

The design is based on linear control, although some special-purpose nonlinear capabililies have been added Matrices used by the real-time software are calculated offlinc in advance, usually incorporating data from the accelerator model with a design noise specirum. The typical design correcls a step function with an exponential lime-constant of 6 feedback iterations. The control algorithm does not include online adaption to changes in the machine responsc or noise spectrum. A "cascarde" capability was added to the feedback system as a later enhancement: $t$ is designed to eliminale overtortection fron: a series of linat launch loops using adaptively calculated transpon matrices.

The user interface to the feedhack system provides it rich variety of conırol. diagnostic and analysis capabilities. Displays summarize the status of all feedback loops in selected geographical areas of the machine as well as details of specified loops. Calculated parameters may he studied on a pulse to pulse basis and over longer periods Diagnostics such as heam jitter estimales and goodness-(1)fil calculations enable operators and physicists to study long-Ierm changes in the machine. From touch panels. uscrs enter control parameters such as setpoints. gain factors. limils and filtering cuts.

\section{APPLICATIONS}

Applications of the system have far exceeded thouc originally planned. Figure I provides an owerves of the types and locations of comirols for the SLC. In addution there are control loops for special projects such as the Final Focus Test Beam. Fixed target experiments and the polarized gun lat. as well as many diagnosuc computeonly loops. Several more isops are planned for the ncu laser wire heam size monilor and lor the PEP-II project.

Launch loops stahilize the beam positions and angles in the linac, injector. damping rings, posison return lisic.

'Wuk supported by the Depannient of Energy conuact DE-AC03-76SF005I5 


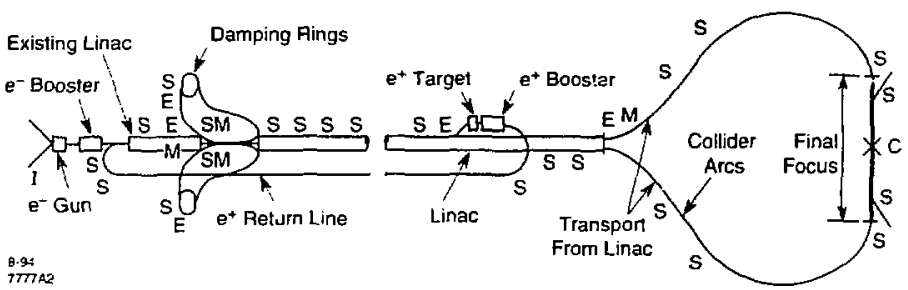

Figure 1: SLC schemalic with fast feedback locations shown. $S=$ steering loop: $E=$ energy control: $I=$ intensity/gun control: $C=$ special purpose loop to maintain beam collisions: $M=$ minimization

collider ARCs and final focus areas using BPM measurements and corrector magnel control. While the system was originally designed for this purpose, it was generalized in order o support a wide variely of measurcment and control devices. including measurcments of gated ADCs, and actuators sich as amplitude conirols, klystron phases and timing delays. With the addition of the polarized gun to the SLC. several feedhack loops werc added to control intensily of the YAG and Ti Sapphire lasers. gur extraction timing. and monitoring of gun-related paramelers such us the polurization asymmetry.

The feedhack afgorithm is hased on linear matrix calculations. hut in some cases there is a need to control actuators which are not linear $w$ ith the controlled states. This is accomplished hy designing matrices to control an imaginaty device which responds linearly. In the real-time software. the matrix equations determine a setting for the imaginary uctuator and eslimate its effect on the states. Given id requested selting for the imaginary actuator, the snecial purpose sofiture then calculates what is needed for the real. nonlincar aclualors in order to accomplish the required control. Control of the beam energy is provided in live SLC localions. some of which require nonlinear actuator calculations. For example, the energy control for the electron hunch which is extracted from the linac to make positrons. is accomplished with an interface to at hardwart-hased feedforward system. The feedformard controls the klysiron phase for qwo linac sectors and is designed to compensatc the energy for intensity variations deceted in the dampin! ring. The feedhack system contrsh the enerty indirectly by varying amplitude controllers which are part of the feedforward. These amplitudes represent quadratic fil cuefficients for energy versus klysiron phase.
Energy control for the electron and positron beams in the linac requires nonlinear control of the klystron phases for two sectors. In order to provide independent encrgy control for the two bearis, this was recently extended to control the timing of the 2 ól linac klystrons and subboosters, called the PSK time. The calculated PSK time is broadcasl aver a specialized network, received by al! of the linac micros, and added to the nominal trigger timing for each klystron and subbouster.

Al the interaction point, the beam dellection angles are controlled to keen the heams in collision. The heam hehaviour is characterized by an S-shaped deflection curve. The slope of the linear portion of the curve (corresponding to small beam-beam separations), along with measurements of the heam deflections and intensities. is used in the special-purpose feedhack calculations. Since the slupe changes with heam size it is periodically determined by an exiernal process which scans ane heam across the other hefore downloading updated paramerers to the feedbach system. For smali separations, the fecdhack controls optimally. within the centra! linear portion of the curve. In those cases where large dislurbances bring the heam-hean separation out to the nonlinear purtions of the curve. the feedhack response is slower, hul it controls correctly and collisions are successfully maintaincd.

\section{MIN]MIZATION}

Minimization is an extension to the fecdback systen which applies where measurements respond parabolically with actuator movernent. In these cases, given a single raw measurement such as a BPM reading. ihere is not enough information for a feedhack to tefl which way in move the actualor, hecause it may the on either side of the paratula. One way to ohlain this information is to move the actuator and ohserve the medsuremenl change. For the SLC 
optimization packages, the actuator is scanned through a range of values and a parabolic fit is perfomed: but this is an invasive procedure. An alternate method implemented in the feedback system is called "dithering" [5]. This involves perturbing the actuator by a tiny amount above and below its nominal setting while taking synchronous beam measurements. After many pulses. an average slope is calculated for the measurement versus the actuator change. The slope of the parahola is linear with the actuator, so the linear feedback calculation is formulated with the calculated stope as a measurement. Minimization is accomplished hy kecping the slope set at zero. but the leedhack syslem is generalized so that the slope can be kepl to any requested setpoint. In the SLC. generalized capatility for dithering and minimization has been developed and demonstrated. The system has been able to perform dithering and control the heam to a stahle point on the parahola. Uniorlunalcly, use of the dithering system has proven to he invasive; the smallest dithering bit sizes cause ulacceplable heam disıurhances.

Howi: ir. a moninvasive minimization feedbeck has been implemented and commissioned. The kicker timing feedhack foop selies on the natural jutter of the ring extraction kick lime (measured with a TDC) to produce slope calculalıon of BPM measurements versus kick lime: dithering is not needed. In order to provide a reasonahl: slope estimalc. 10.000 pulses of dala are averaged; at a BPM nicasurcment ratc of 60 Her17, it takes almost 3 minutes to produce a single calculation. Commissioned only a lew days before the end of the last SLC run. the loop has already heen shown to improve machine performance
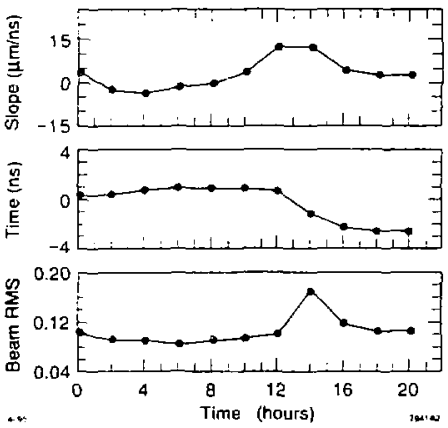

FIGL:RE 2: Munimuastisn kicker timing reedback improves she RMS besm jitler
Figure 2 shows the feedback response to changing ring exiraction conditions: the RMS beam jitter (calculated by a downstream feedhack loop) increases until the feedhack corrects the kicker timing, which reduces the jitter to its normal value. Note that the feedback response is slow duc to an intentionally conservative initial design.

\section{PERFORMANCE ISSUES}

In the pasi year. progress has been made in identifying and analyzing SLC feedback performance issues[4]. Of particular interest is the response in the linac. There was concern that imperfections in the feedback modeling and the large number of loops may result in amplification of beam noise for some frequencies. However, with the finlle sampling rate used in the feedhack system. even ideal conditions would result in noise amplification for some frequencies. Techniques were devcloped to analyze the feedback response for both single loops and for the lina system as a whole. Several sources of feedhack imperfection were identified and studied.

The matrices for a taunch loop incorporate a transport model for that area of the accelerator. including transport clements between BPM readings, heam positions and angles, and correclor settings. In some cases, the online model does not accuratcly itflect the accelerator responsc. so feedback calibration is needed. This is accomplished hy moving each corrector one at a time birough a range al valucs and mearuring the fitted beam positions and angles for each setting. The slopes of these states versus the corrector setlings are incorporated into new feedhack matrices. Recent sofiware improvements have made the calibration system easier to use. hut it remains an invasive procedure for which il is difficult to get sufficient heam timc. In a few areas of the machine. the model is so poor that the feedback cannot he used without calibration. In marginal cascs. imperfect modeling simply degrades the feedhack performancc.

Another performance consideration is the limi response of the correctors. The design for linat loops assumes that corrector changes are implemented with i delay of three fecdback iterations: one iteration is allowed for calculations and communication. with two additional iterations for the magnelic field to change. Recent measurements indicale that typical linac correcturs tan move from 1010907 of a requested change wilhin ahoul 9 120-Hertz pulses. For most of the linac loops, which run a 20 Heriz, the response is close enough to thil used in the feedhack design. However. for the last loop in the linji: which was upgraded to nu at 60 Herta. the correctur response is relatively slow and not adequalciy modeted. Simulations for the standard feedhack design. shown in 
figure 3 , indicale that when corrector response is slow compared to the design feedhack control of 6 pulses, there is performance degradation. Furthemore, the response becomes morc sensitive to othe $\boldsymbol{f}$ ctors such as imperfect modeling. Near the end of the lası SLC run. attempis were made 10 design matrices with a better model of the slow corrector respnnse. Tests of the new design showed improved feedhack response. hut other problems made it operationally unacceptable. Additional work is nceded.

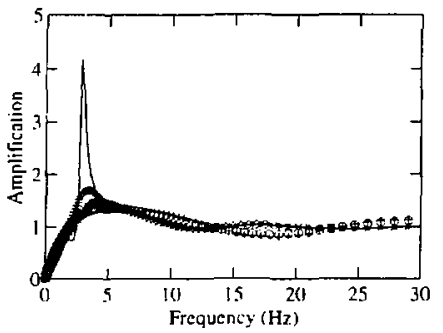

Figure 3: Simulations of feedhack response with slow: corrector speeds and imperfect calibrations. Plots shown are for the ideal case (o), slow correctors $(*)$, poor modeling $(+)$, and the combination of slow correctors with poor modeling (-).

Figure 4 shows cslimates of feedhack response for the series of linac launch loops. The response is measured by inducing a step function upstream of the linac, first with the feedhacks on and then with the feedhacks off. Fitted heam position data for thoth cases is acquired for several hundred consecutive pulses. The FFTs for hoth data sels are calculated and the ratio is plotled. Unfortunately this meisurement is roisy. An alternate technique involves inducang sune uaves over a range of known frequencics and measuring the resulting umplitudes with ieedback on and off. The sine wave technigue produces tlearner results less invasively, but it is more time-consuming. Also shown in figure 4 are simulations for feedhack performance. Note that the "ideal" simulation assumes that the acceleratsir model is perlect. conectors are an last as modeled, that als of the Iopps are operating with gain factors of 1.0 and that the cascide system is working perfectly. This is identical to the ideal simulason for a single loop. An initial allempt at a more realistie sinulation includes effects of imperfect modeling. low gain tactors and imperfecl cascade performance. More work needs to be done to measure. simulate and hopefully to optimize the performance of the linac loops as a system.

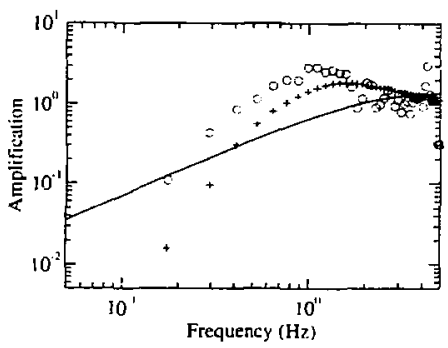

Figure 4: Measmement and simulations of feedback response (on/olf) for the system of linac loops. Plots shown are for the ideal case (-), measured data taken from a ratio of FFTs $(0)$, and an attempl at a realistic simulation $(+)$.

\section{"CASCADED" FAST FEEDBACK}

As shown in figure 1, steering in the SLC linac is controlied by a series of feedback loops. In the original system. these loops were all controlling the same parameters; this resulted in problems with overconection of upsiream perturbations and amplification of heam noise. This effect was predicled in the initial feedhack design simulations and the cascade system was designed lo corret this prohlem. Now. after receiving new measurements on each heam pulse. each linac loop sends its caiculated stales to the nexi downstream loop, and receives the currem stales from its upstrcam neightor. The downstream loop perfolms conrections hased on the differences between the states of the upsticam and dounstream loops. Therefore each loop should correct only the perumbations insisated immedialely upsircarn of it. These corrections depend upon a reliable method for mathematically transporting the positions and angles at one point to the downstream locition. The model is nor good enough over these distances. so adaptive methods arc used to dynamicall! update the transpon matrices. The adaption calculalions are based upon the SEquential Regression (SER) algorithm[7]. adapied for use in the SLC feedback system[2].

Cascade performance can he characierized hy rejecliun ratios. This is the fraction of an incoming merlurbation which is seen and corrected by each leedhack lowp. 
Idcally, for a loop immediatcly downstream of a perturbation. the rejection ratio should be onc. and for the further-downslream loops the rejection ratio should be zero. Poor rejection ralios are an indication that the adaplively-calculated transpor matrices do not perfectly model the actual beam transport.

Initially when the cascade system was commissioned. the rejection ratios for downstrcam loops indicaled excellent response: typical downstream rejection ratios were 10\%. In the past year, cascade performance has been revisited; recently the rejection ratios ranged from very good (10-25\%) up to more than $50 \%$ for some cases. If al] of the fecdback loops ran with the full corrections, ihis would result in ovcrshoot and ringing: as a result, the gain factors have been lowered so that each Joop only performs a fraction of the required correction on each pulse.

Several possitilities were investigaled in attempts to understand the cascade performance. If the machine were dominaled by phasc jitter instead of betalron jitter. this would produce incorrect transport. since the adaplive process rclies on correlations of perturbations between Inops. Furlhermorc. at recent SLC beam intensities. wakeficlds cause nonlincar transport effects which have been shown to the a significant problem for the cascade system. In one case the transport magnitude from one feedhack loop to the next varied by $50 \%$ for different penurhation source lecations, hoth in simulation and from beam measurements. Finally, during low curren siudics. poorer BPM resolutions appeared to degraac the adaption results hy introducing uncorrelated noise which pulis the adaplively-calculated transport magnitudes toward zero. Further study is reeded in this area. However, anolysis of the wakelield effecl indicates that perfect cascode periormance cannet he achicved with this architecture under curent SLC conditions. since the beam transport is depencient on the source location of a perlurbalion and the implemented cascade design does nol provide this infornation.

\section{CONCLUSIONS}

The fust feedback system bas hecome essential for successful opcration of the SLC. While its performince characteristics require further study and improvement. it provides many positive comtributions for operations. The large number of lesdhack lones decouples the various areas of the SLC. supportung machinc studies by allowing downslream loops lo compensalc for incoming disturhanes. In the linac. heam emittance is aptimized by moxing lesdhack selpoints lo produce closed orbit humps. With the lecuback system, machine reproducitility is improved and smowher starup after outages is seen.
Efficiency was improved by a factor of iwo in the first year of feedback operation. Operators steer much less often and there is a significant decrease in operator adjustments. This allows the operators time for more suble tuning and contributes to increased luminosity.

It is hoped that future colliders will benefit from the substantial base of beam experience with the SLC feedback system. Comparable or superior capabilities are likely to he required: realistic feedback performance estimates as well as designs for fulure systems should include consideration of the challenges faced in the SLC system.

\section{ACKNOWLEDGEMENTS}

The SLC feedback sysiem has henefilted from the contributions of many operators and physicists as well as hardware and software engineers. We are graleful to Chris Traller for preparation of the manuscript.

\section{REFERENCES}

[1] L. J. Hendrickson et al. "Generalized fast feedhack sysiem in the SLC". In Proceedings of the International Conference on Accelerarors and Largi' Experimental Physics Control Systems, Stanford Linear Accelerator Center. Novemher 1991. SLAC. PLB-568.3.

[2] T. Himcl et al. "Adaptive cascaded heam-hased reedback at the SLC". In Proceedings of the IEEE Particle Accelerator Conference, Stanford Lincar Accelerator Center. May 1993. SLAC.PUB-612.5.

[3] K. Krauter and D. Nelson . "SLC's Adaptation of the ALS high performance serial link". In Proceedings of the IEEE Farticle Accelerasor Conference. Stanford Lincar Accelerator Center. May 1991.

14] M.G. Minty el al. "Optimizarion of feedhath performance at the Sianford Linear Collider". In Procedings of this Conference. Stantord Lincar Acceleralor Cencer. May Iyys

[5] M.C. Ross, T. Himel, L.J. Hendrickson. and E Miller. "Precise system stahitization as SLC using" dither lechniques". In Proceedings of the IEEE Parricie Accelerator Conference, Sianford Linear Accelerator Center. May 1993. SLAC.PUB-6i02.

(6) F. Rouse. T. Himcl. L.J. Hendrickson, and H. Shoace: "Use ol digital control theory state space formalism for feedhack a SLC". In Proceedings of tht' IEEE Particle Accelerator Conference. Sianford Lintur Accele ator Centcr, May 1991. SLAC-PLB-5470.

[7] Bemard Widrow and Sumucl D. Stearns Adantise Signal Processing. Prentice-Hail. Inc. 1985. 


\section{DISCLAIMER}

This report was prepared as an account of work sponsored by an agency of tbe United States Government. Neither the United States Government por any agency thereof, nor any of their employees, makes any warranty, express or implied, or assumes any legal liability or responsibility for the accuracy, completeness, or usefulness of any information, apparatus, product, or process disclosed, or represents that its use would not infringe privately owned rights. Reference herein to any specilic commercial product, process, or service by trade name, trademark manufac. eurer, or otherwise does not necessarily constitute or imply its endorsement, recommendation, of favoring by the United States Governmeat or any agency thereof. The views and opinions of authors expressed herein do not necessartly state or reflect those of the United States Government or any agency thereof. 